\title{
Analysis of heat transfer coefficient for variable spatial orientation of a minichannel with an enhanced surface at incipience of boiling
}

\author{
Magdalena Piasecka ${ }^{1, \mathrm{a}}$ and Beata Maciejewska ${ }^{2}$ \\ ${ }^{1}$ Kielce University of Technology, Faculty of Management and Computer Modelling, Al. 1000 - lecia P.P. 7, \\ 25-314 Kielce Poland \\ ${ }^{2}$ Kielce University of Technology, Faculty of Mechatronics and Mechanical Engineering, Al. 1000 - lecia P.P. 7 , \\ 25-314 Kielce Poland
}

\begin{abstract}
The paper presents flow boiling heat transfer of FC-72 in $1 \mathrm{~mm}$ depth, $40 \mathrm{~mm}$ width minichannel where a foil with evenly distributed recesses on one side acts as a heating surface. The minichannel is set at various angles, i.e. $0,45,90,135$ and 180 degrees inclinations in relation to the horizontal plane. The plain side of the foil is observed to determine the surface temperature by liquid crystal thermography. Two heat transfer models: one- and two-dimensional are proposed to calculate local heat transfer coefficients. In the twodimensional approach the inverse problem in the heating wall is solved by the semi-analytical method based on Trefftz functions in subareas, abbreviated to the nodeless Trefftz method. Local values of heat transfer coefficient on the surface between the heating foil and boiling liquid were calculated on the basis of the thirdkind boundary condition. The influence of minichannel orientation on heat transfer coefficient at boiling incipience region values were analyzed. The same tendencies in the results were observed for the two applied methods. The one-dimensional approach seems to be less sensitive to measurement errors. The polynomial smoothing of the results applied in the two-dimensional method can affect the rounding values of coefficient.
\end{abstract}

\section{Introduction}

An increasing number of high-tech heat exchange devices are based on heat transfer to fluid during flow boiling in minichannels of various geometry and spatial orientation. Mini heat exchangers are used to provide higher cooling. Recently, heat transfer in small channels has been dealt with significant attention, especially for application to electronics cooling. Owing to the change of the state which accompanies flow boiling in small channels, it is possible to obtain a high heat flux at small temperature difference between the heating surface and the saturated liquid and, at the same time, retain small dimensions of heat transfer systems. The use of microstructured heating surfaces allows additional intensification of the heat transfer process.

\section{Experiment}

\subsection{Experimental stand}

The test section with a minichannel (1, figure 1a) $1 \mathrm{~mm}$ deep, $40 \mathrm{~mm}$ wide and $360 \mathrm{~mm}$ long, is the most important part of the system. The heating element (2) is made from alloy Haynes 230 and microstructured on one side (8) in direct contact with the fluid flowing in the channel (FC-72). It is possible to observe the channel surfaces through two glass panes. One pane (4b) allows observing foil temperature changes owing to a liquid crystal layer (3) deposited on the plain side of the foil. The other glass plane (4a) allows conducting two-phase flow visualization on the microstructured foil side. Ktype thermocouples are installed at the inlet and outlet of the minichannel (7). The minichannel is set at various angles, i.e. $0,45,90,135$ and 180 degrees inclinations in relation to the horizontal plane (figure $1 \mathrm{~b}$ ).

The data and image acquisition system with digital cameras, a data acquisition station, a computer with specialized software and lighting systems are the essential parts of the research equipment. The flow loop is comprised of a test section, a rotary pump, a compensating tank, a heat exchanger, a filter, rotameters and a deaerator. The schematics of the main loops and the data acquisition system are presented in [1-7].

On one side of the heating foil, micro-recesses were formed and distributed uniformly on the foil. These recesses (figure 1c) were performed by laser drilling [8]. The diameter of the single micro-recess is usually $10 \mu \mathrm{m}$, its depth is $3 \mu \mathrm{m} .5 \div 7 \mu \mathrm{m}$ high layers of melted metal deposit annularly around the recesses, forming structures

\footnotetext{
${ }^{\mathrm{a}}$ Corresponding author: tmpmj@tu.kielce.pl
} 
that can be named as "craters". Micro-recesses are evenly distributed every $100 \mu \mathrm{m}$ in both axes.
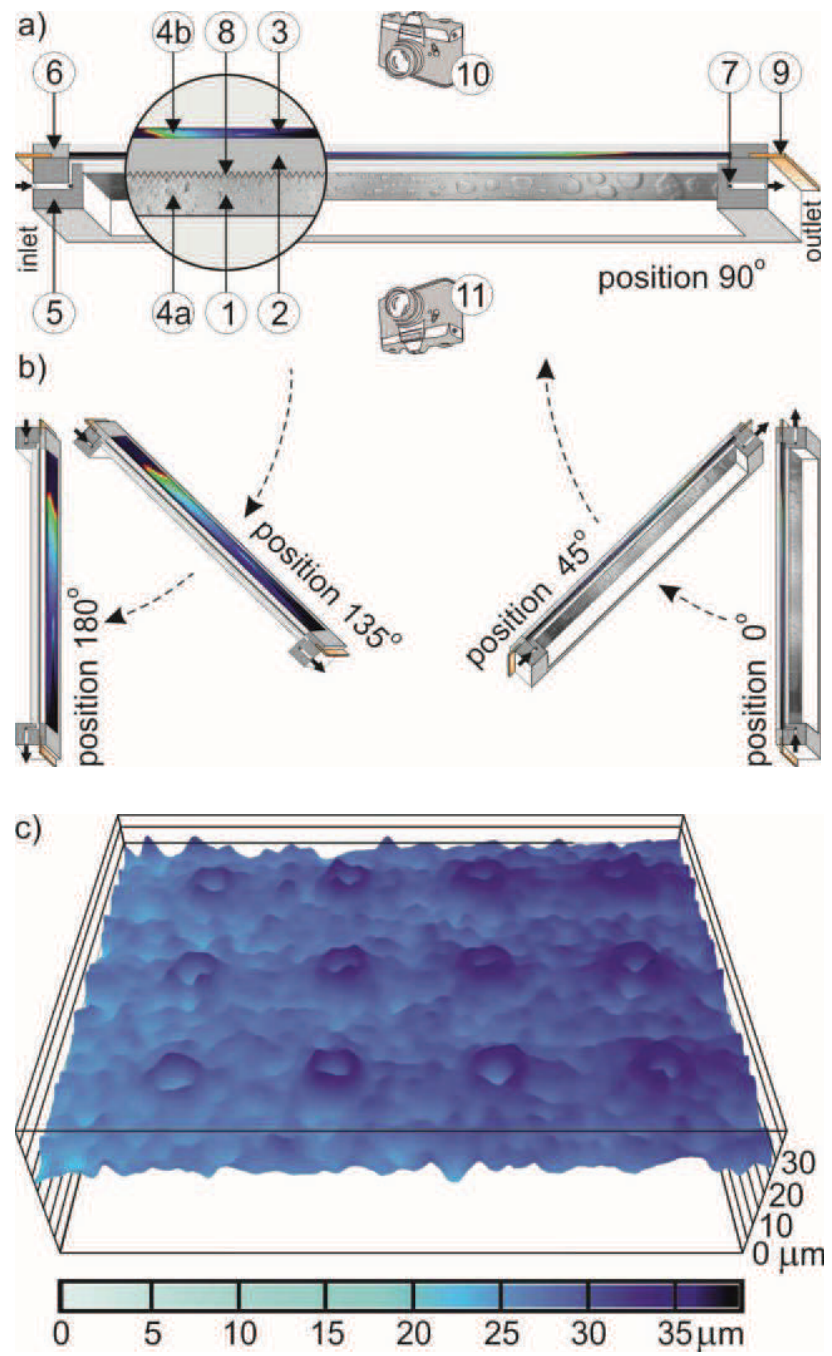

Figure 1. a) The diagram of the test section: 1 - minichannel, 2 - heating foil, 3 - liquid crystal layer, 4a,b - glass plate, 5 - channel body, 6 - front cover, 7 - thermocouple, 8 - enhanced side of the foil, 9 - copper element, 10 - digital camera, 11 - digital SLR camera, the vertical minichannel, position $90^{\circ}$; b) remaining analysed minichannel positions; c) $3 \mathrm{D}$ topography of the enhanced sampled area with microrecesses

\subsection{Experimental methodology}

Fluoroinert FC-72 flows laminarly along the minichannel. The gradual increase in the electric power supplied to the heating foil results in an increased heat flux transferred to the fluid in the channel. This leads to the incipience and then to the development of nucleate boiling.

Thanks to the liquid crystal layer located on its surface contacting the glass it is possible to measure the temperature distribution on the heating wall. Application of the liquid crystal thermography for the detection of two-dimensional heating surface temperature distribution must be preceded by colour (hue) - temperature calibration. Flow structure is observed simultaneously in the opposite side of the minichannel.

Uncertainty analyses including evaluation of the accuracy of heating foil temperature measurements with liquid crystals thermography was done in detail in $[3,7]$.

\section{Mathematical models}

\subsection{One-dimensional model}

In the simple one-dimensional model [1] heat transfer coefficient for the subcooled boiling and boiling incipience region was determined as follows:

$$
\alpha(x)=\frac{I \cdot \Delta U / A_{F}}{T_{F}(x)-T_{f}(x)-\frac{I \cdot \Delta U}{A_{F}} \cdot \frac{\delta_{F}}{\lambda_{F}}},
$$

where $I$ - current, $U$ - voltage drop, $A_{F}$ - foil surface, $\lambda_{F}-$ foil thermal conductivity, $\delta_{F}-$ foil thickness, $T_{F}$ - foil temperature, $T_{f}$ - fluid temperature calculated with the assumption of linear temperature distribution of the fluid flowing along the minichannel (measurement of the liquid temperature at minichannel inlet and outlet), $x$ - the distance from the channel inlet to outlet.

\subsection{Two-dimensional model}

In $2 \mathrm{D}$ approach the values of heat transfer coefficients are calculated from the formula:

$$
\alpha(x)=\frac{-\lambda_{F} \frac{\partial T_{F}\left(x, \delta_{G}+\delta_{F}\right)}{\partial y}}{T_{F}\left(x, \delta_{G}+\delta_{F}\right)-T_{f}(x)} .
$$

It is assumed that stationary temperature distributions in the heating foil is described, as in [9], by Poisson equation:

$$
\nabla^{2} T_{F}=-\frac{q_{V}}{\lambda_{F}} \text { for }(x, y) \in \Omega_{F},
$$

where $\Omega_{F}=\left\{(x, y) \in R^{2}: x_{1}<x<x_{P}, \quad \delta_{G}<y<\delta_{G}+\delta_{F}\right\}$,

and the boundary conditions:

$$
\begin{gathered}
T_{F}\left(x, \delta_{G}\right)=T_{G}\left(x, \delta_{G}\right), \\
\lambda_{F} \frac{\partial T_{F}}{\partial y}\left(x, \delta_{G}\right)=\lambda_{G} \frac{\partial T_{G}}{\partial y}\left(x, \delta_{G}\right), \\
T_{F}\left(x_{1}, \delta_{G}\right)=T_{1}, \\
T_{F}\left(x_{P}, \delta_{G}\right)=T_{P}, \\
T_{F}\left(x_{p}, \delta_{G}\right)=T_{p} \text { for } p=1,2, \ldots, P,
\end{gathered}
$$

where $x_{1}$ is the location of the primary temperature measurement on the boundary $y=\delta_{G}, x_{P}$ - location of 
the last temperature measurement, $T_{p}-$ value of temperature measurement, $P$ - number of temperature measurements, $\lambda_{G}$ - the thermal conductivity coefficient of the glass barier.

The auxiliary temperature $T_{G}$ of the glass barrier is obtained by solving Laplace's equation [9]:

$$
\nabla^{2} T_{G}=0 \text { for }(x, y) \in \Omega_{G},
$$

where $\Omega_{G}=\left\{(x, y) \in R^{2}: 0<x<L, \quad 0<y<\delta_{G}\right\}$,

with the boundary conditions:

$$
\begin{gathered}
\frac{\partial T_{G}}{\partial y}(x, 0)=\frac{\partial T_{G}}{\partial x}(0, y)=\frac{\partial T_{G}}{\partial x}(L, y)=0, \\
T_{G}\left(x_{p}, \delta_{G}\right)=T_{p} \text { for } p=1,2, \ldots, P,
\end{gathered}
$$

where $L$ denotes the length of the glass barrier.

The inverse problem (3-8) was solved by means of the Beck method in connection with the Trefftz method. In detail, this method was described in $[3,11]$. It bases on the transformation of the inverse problem into the direct problems by means the so-called the sensitivity coefficients [12].The foil temperature $T_{F}$ was determined by the following formula:

$$
\begin{gathered}
T_{F}\left(x, y, q_{1}, . ., q_{J}\right)= \\
=T_{F}\left(x, y, q_{01}, . ., q_{0 J}\right)+\sum_{j=1}^{J} Z_{j}(x, y)\left(q_{j}-q_{0 j}\right),
\end{gathered}
$$

where $Z_{j}(x, y)=\frac{\partial T_{F}}{\partial q_{j}}$ are sensitivity coefficients, $q_{j}$ are constant heat fluxes on the boundary $y=\delta_{G}+\delta_{F}$.

The direct problems resulting from the substitution of expression (12) both to eq. (3) and to conditions (5-7) were solved by using the Trefftz method.

To determine $q_{j}$ in formula (12) the appropriate functional was minimized.

The mean relative error of heat transfer coefficients was determined in the same way as in [3].

All the mean relative errors $\sigma$ computed for various channel positions are summarized in Table 1.
Table 1. Mean relative errors $\sigma$ [\%] of the heat transfer coefficient obtained for various channel positions.

\begin{tabular}{|c|c|c|c|c|c|}
\hline $\begin{array}{r}\text { Set } \\
\text { No. }\end{array}$ & $\begin{array}{c}\text { Vertical } \\
\text { position, } \\
90^{\circ}\end{array}$ & $\begin{array}{c}\text { Horizontal } \\
\text { position, } \\
180^{\circ}\end{array}$ & $\begin{array}{c}\text { Horizontal } \\
\text { position, } \\
0^{\circ}\end{array}$ & $\begin{array}{c}\text { Inclined } \\
\text { position, } \\
45^{\circ}\end{array}$ & $\begin{array}{c}\text { Inclined } \\
\text { position, } \\
135^{\circ}\end{array}$ \\
\hline$\# 1$ & 3.21 & 3.31 & 3.04 & 3.16 & 3.18 \\
\hline$\# 2$ & 3.11 & 3.52 & 2.97 & 3.16 & 3.13 \\
\hline$\# 3$ & 3.06 & 2.95 & 2.80 & 3.28 & 3.15 \\
\hline$\# 4$ & 3.01 & 3.35 & 2.82 & 2.66 & 3.09 \\
\hline$\# 5$ & 2.99 & 2.79 & 2.73 & 2.69 & 3.15 \\
\hline$\# 6$ & 2.93 & 2.65 & & 2.65 & 2.97 \\
\hline$\# 7$ & 3.01 & 2.67 & & 2.63 & 2.94 \\
\hline$\# 8$ & 2.86 & 2.78 & & 2.66 & 2.94 \\
\hline$\# 9$ & 3.11 & 2.7 & & 2.66 & 2.94 \\
\hline$\# 10$ & 3.10 & 2.65 & & 2.73 & 2.96 \\
\hline$\# 11$ & & & & & 2.90 \\
\hline$\# 12$ & & & & & 2.85 \\
\hline
\end{tabular}

\section{Results}

Figures $2 \div 6$ show the local values of the heat transfer coefficient solved by means of the one- and twodimensional approaches (1D and 2D) for different positions of the minichannel. Data were obtained for subcooled boiling at boiling incipience region when heat flux supplied to the heating wall increases. Main experimental parametres are as following:

- $\quad$ mass flux $211 \mathrm{~kg} \mathrm{~m}^{-2} \mathrm{~s}^{-1}$,

- $\quad$ inlet pressure $125 \mathrm{kPa}$,

- $\quad$ inlet liquid subcooling $42 \mathrm{~K}$.

Respective data are shown in:

- $\quad$ figure 2 - for the vertical minichannel, position $90^{\circ}$,

- figures 3 and 4 - for the horizontal minichannel, position $180^{\circ}$ (figure 3 ) and position $0^{\circ}$ (figure 4 ),

- figures 5 and 6 - for two inclined positions of the minichannel: position $45^{\circ}$ (figure 5) and position $135^{\circ}$ (figure 6). 

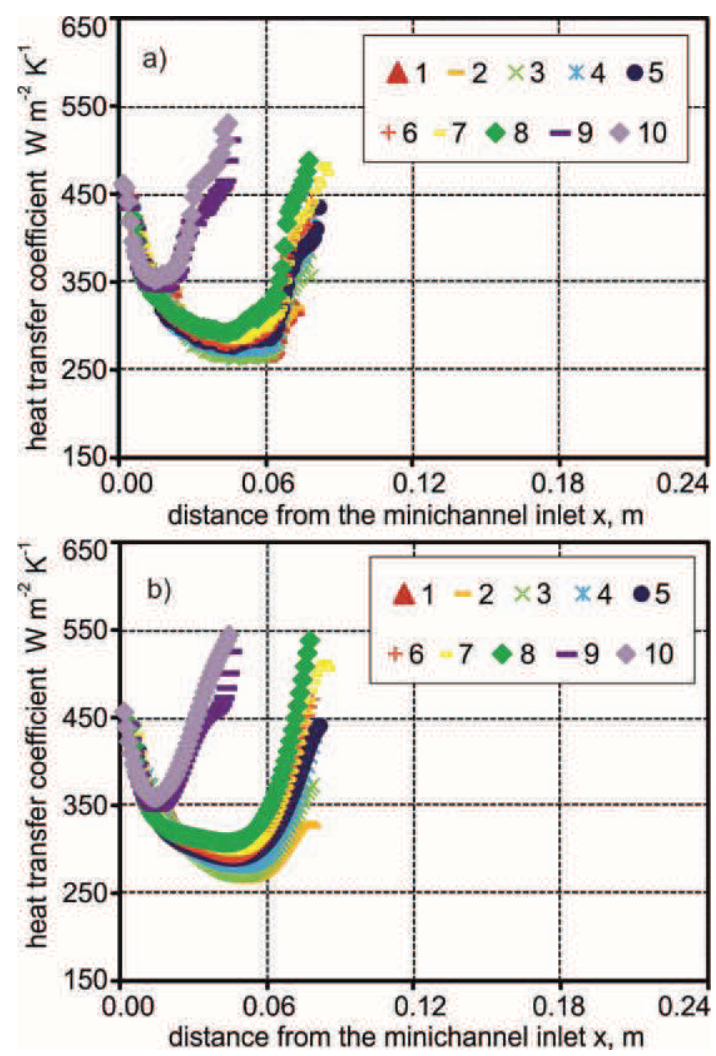

Figure 2. Heat transfer coefficient dependences on the distance along the minichannel length determined from: a) 1D approach, b) $2 \mathrm{D}$ approach; the vertical minichannel, position $90^{\circ}$, heat flux density: $11.78 \div 17.70 \mathrm{~W} \mathrm{~m}^{-2}$
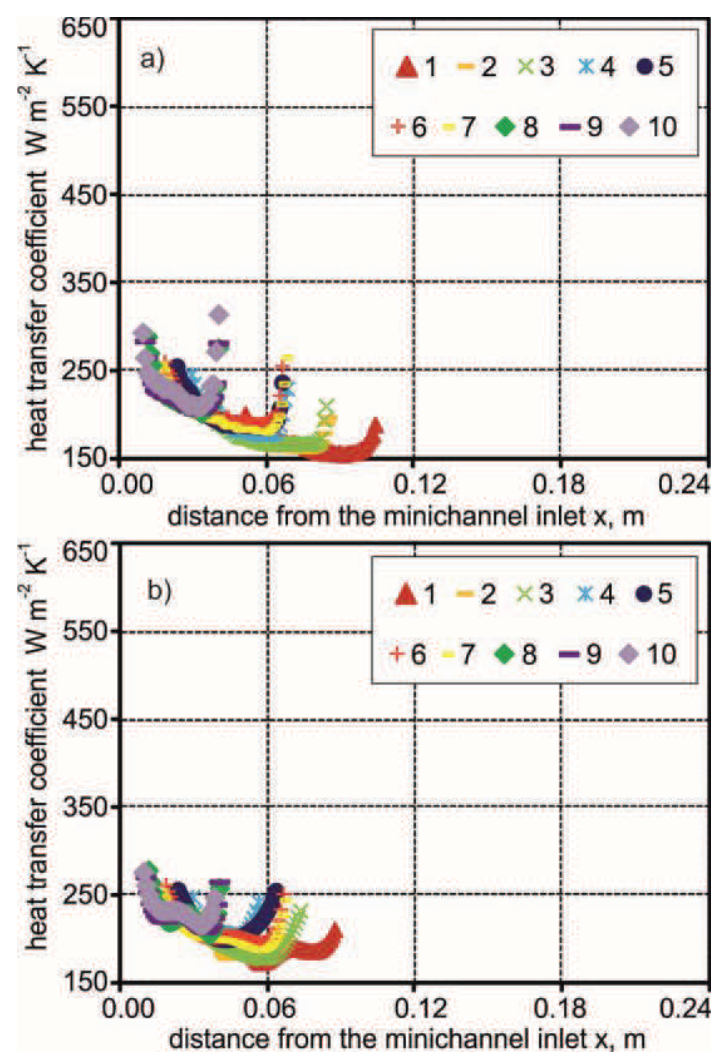

Figure 3. Heat transfer coefficient dependences on the distance along the minichannel length determined from: a) 1D approach, b) $2 \mathrm{D}$ approach; the horizontal minichannel, position $180^{\circ}$, heat flux density: $7.13 \div 11.63 \mathrm{~W} \mathrm{~m}^{-2}$
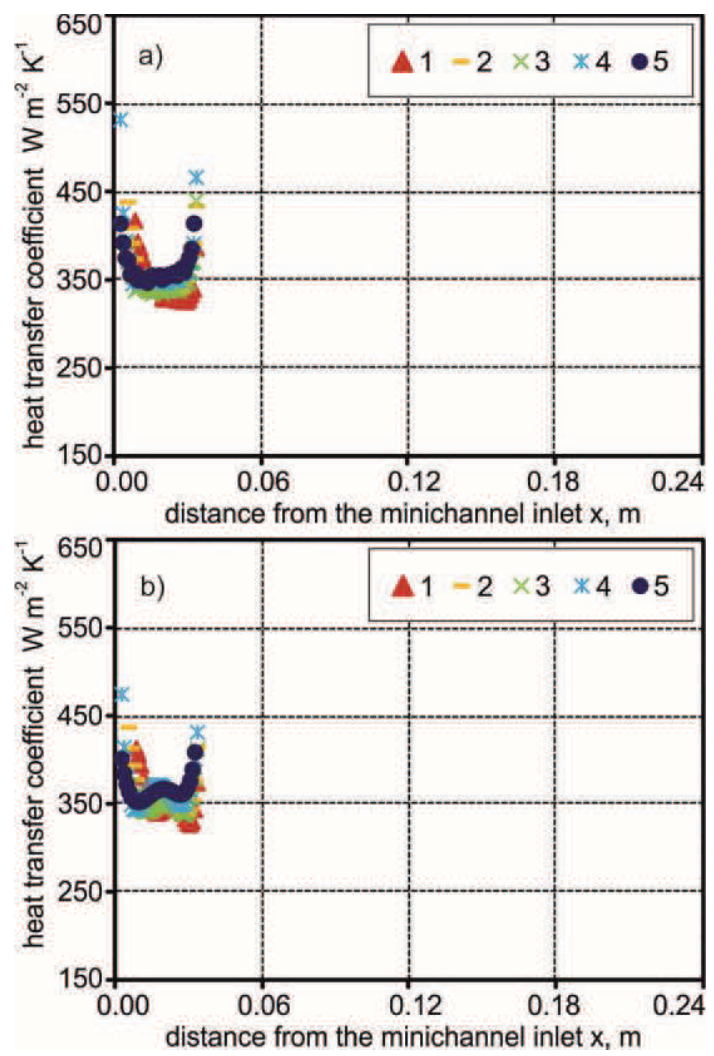

Figure 4. Heat transfer coefficient dependences on the distance along the minichannel length determined from: a) 1D approach, b) $2 \mathrm{D}$ approach; the horizontal minichannel, position $0^{\circ}$, heat flux density: $14.73 \div 17.44 \mathrm{~W} \mathrm{~m}^{-2}$
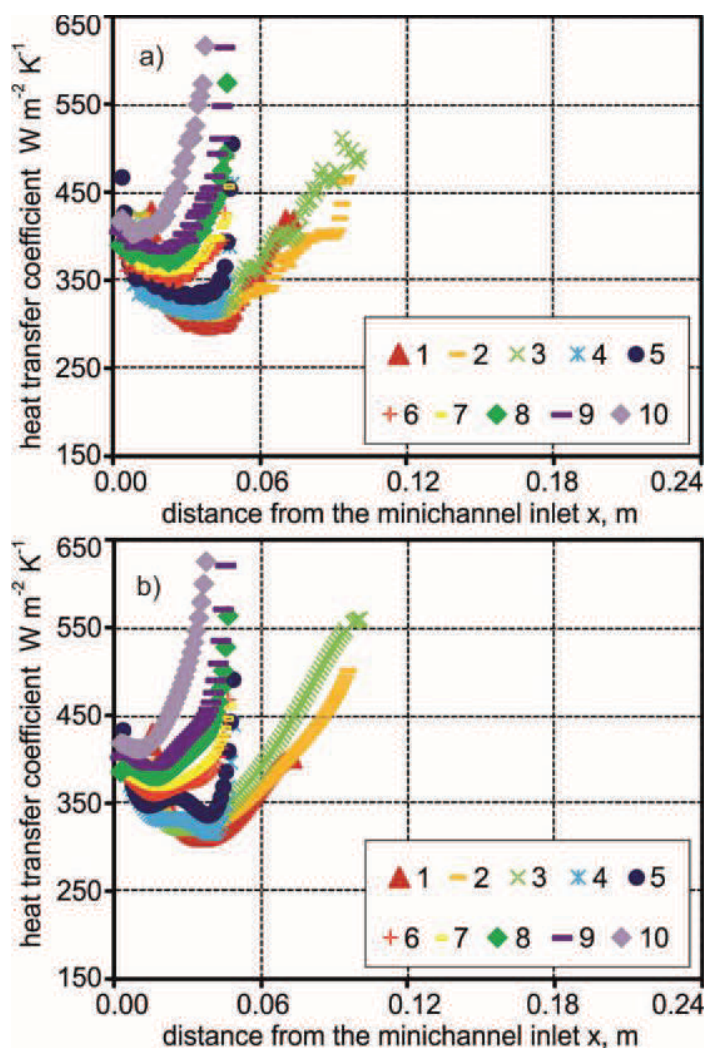

Figure 5. Heat transfer coefficient dependences on the distance along the minichannel length determined from: a) 1D approach, b) $2 \mathrm{D}$ approach; the inclined minichannel, position $45^{\circ}$, heat flux density: $14.27 \div 22.45 \mathrm{~W} \mathrm{~m}^{-2}$ 

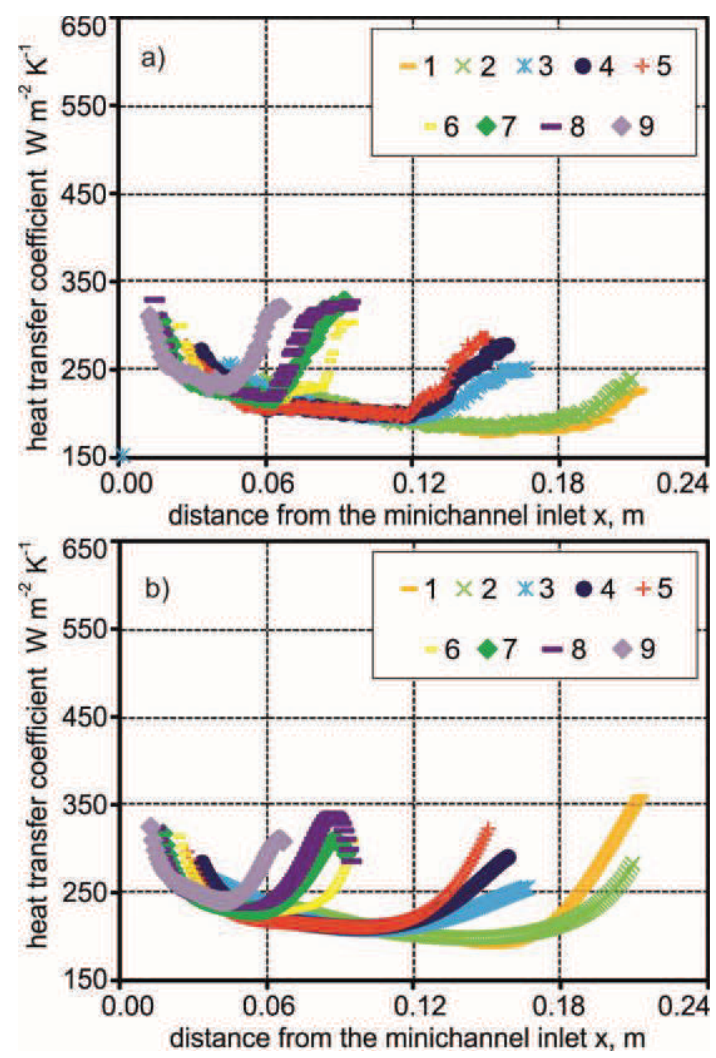

Figure 6. Heat transfer coefficient dependences on the distance along the minichannel length determined from: a) 1D approach, b) $2 \mathrm{D}$ approach; the inclined minichannel, position $135^{\circ}$, heat flux density: $8.38 \div 12.56 \mathrm{~W} \mathrm{~m}^{-2}$

\section{Observations and Conclusions}

Experimental tests were carried out in similar thermal and flow conditions assumed for the boiling incipience region at various orientations of the test section with the minichannel enabling a comparative data analysis.

Analysis of the heat transfer coefficient dependence along the selected minichannel length leads to the conclusion that the heat transfer coefficient starts rapidly to increase in the boiling incipience region.

The comparative data analysis shows that the highest values of the heat transfer coefficient were observed for the inclined minichannel, position $45^{\circ}$ and for the vertical minichannel, position $90^{\circ}$. The lowest values of the heat transfer coefficient were noticed for the horizontal minichannel, position $180^{\circ}$ and for the inclined minichannel, position $135^{\circ}$. Experiments for minichannel positions $30^{\circ}$ and $60^{\circ}$ could be added to formulate more detailed conclusions.

After the analysis of the local heat transfer coefficient calculated by two different methods (according to onedimensional and two-dimensional models) it was noticed that similar values of the transfer coefficient were found, and distributions of the heat transfer coefficients are of similar nature. Albeit, the same sets of the results were observed for the two applied calculation methods, those obtained in the one-dimensional approach are slightly similar to the case of the two-dimensional one. The polynomial smoothing of the results is applied in the twodimensional method which can affect the rounding values of heat transfer coefficient especially in those regions of the chart where there are few measurement points. The one-dimensional approach seems to be less sensitive to measurement errors, because simple mathematic operations are applied for calculating.

In order to compare experimental heat transfer coefficients to results of other authors, measurement series for three orientations of the channel with microstructured heating wall were selected: horizontal (positions $0^{\circ}$ and $180^{\circ}$ ) and vertical (position 90 $0^{\circ}$ ) [13] It was found that most correlations enables the predicting of heat transfer coefficient within an acceptable error limit $( \pm 30 \%)$ only in the specific orientation of the minichannel. Own correlation, separately for subcooled and saturated flow boiling was also presented.

\section{Acknowledgments}

The research has been financially supported by the National Scientific Center granted on the basis of decision No. DEC-2013/09/B/ST8/02825.

\section{References}

1. M. Piasecka, Int. J. Heat and Mass Transf. 66, $72-488$ (2013)

2. M. Piasecka, B. Maciejewska, Exp. Thermal Fluid Sci. 44, 23-33 (2013)

3. M. Piasecka, B. Maciejewska, Exp. Thermal Fluid Sci. 38, 19-32 (2012)

4. M. Piasecka, Heat Mass Transf. 49, 261-271 (2013)

5. M. Piasecka, Exp. Heat Transf. 27, 231-255 (2014)

6. M. Piasecka, Heat Transf. Eng. 35 (10), 903-912 (2014)

7. M. Piasecka, Metrology Meas. Sys. XX, 205-216 (2013)

8. M. Piasecka, Adv. Material Research 874, 95-100 (2014)

9. S. Hożejowska, R. Kaniowski, M.E. Poniewski, Int. J. Numer. Methods Heat Fluid Flow 24, 811-824 (2014)

10. S. Hożejowska, M. Piasecka, Heat Mass Transf. 50 1053-1063 (2014)

11. B. Kruk, M. Sokala, J. Appl. Math. Mech., ZAMM 81 945-946 (2000)

12. J. V. Beck, B. Blackwell, C. R. St. Clair Jr., Inverse heat conduction-ill-posed problems (Wiley Interscience Publ., New York, 1985)

13. M. Piasecka, Int. J. Heat and Mass Transf. 81, 114-121 (2015) 